This article is licensed under the Creative Commons Attribution-NonCommercial 4.0 International License (CC BY-NC) (http://www.karger.com/Services/OpenAccessLicense). Usage and distribution for commercial purposes requires written permission.

\title{
A Bile Duct Stone Formation around a Fish Bone as a Nidus after Pancreatoduodenectomy
}

\author{
Tomoki Sakakida Hideki Sato Toshifumi Doi Takumi Kawakami \\ Yoshikazu Nakatsugawa Ken Nishimura Shinya Yamada \\ Hideki Fujii Naoya Tomatsuri Yusuke Okuyama Hiroyuki Kimura \\ Norimasa Yoshida
}

Gastroenterology Division, Japanese Red Cross Society Kyoto Daiichi Hospital, Kyoto, Japan

\section{Keywords}

Bile duct stone $\cdot$ Fish bone $\cdot$ Foreign body Pancreatoduodenectomy

\begin{abstract}
We report a rare case of bile duct stone formation around an ingested fish bone as a nidus after pancreatoduodenectomy. A 78-year-old woman was admitted to our department for fever and epigastric pain. Abdominal computed tomography revealed an elongated bile duct stone containing a linearly shaped foreign body of bone density. Enteroscopic lithotomy was performed using single balloon enteroscopy to safely remove the stone and foreign body from the bile duct. The foreign body was determined to be a fish bone by pathological examination and component analysis.

(C) 2018 The Author(s)

Published by S. Karger AG, Basel
\end{abstract}




\section{Case Reports in Gastroenterology}

\section{Introduction}

Numerous factors are thought to influence the origin of common bile duct stones. One of the factors is a foreign body in the bile duct, though this is uncommon and rarely referred to in the literature. Sporadic reports have been published regarding fish bones, metal clips, unabsorbable suture material, migrated stents, and parasites which act as a nidus for stone formation. The phenomenon is even more unusual among patients who have undergone pancreatoduodenectomy. In most of these cases, foreign bodies are internal stent tubes for postoperative treatment. Endoscopic and surgical extraction of these foreign bodies is imperative to prevent fatal complications of obstructive jaundice, especially cholangitis and biliary sepsis.

Herein, we report an unusual case of transient obstructive jaundice and acute cholangitis due to a common bile duct stone formed around an ingested fish bone, for which endoscopic therapy was successful.

\section{Case Report}

A 78-year-old woman was admitted to our department for fever and epigastric pain. She had had pancreatoduodenectomy for duodenal carcinoma 9 years ago. On admission, she had a fever of $38.0^{\circ} \mathrm{C}$, slight jaundice in the conjunctiva, and mild epigastric tenderness. Additional findings included elevated levels of hepatobiliary enzymes: aspartate aminotransferase, $85 \mathrm{IU} / \mathrm{L}$; alanine aminotransferase, $77 \mathrm{IU} / \mathrm{L}$; alkaline phosphatase, 2,498 IU/L; and $\gamma$ glutamyl transpeptidase, $627 \mathrm{IU} / \mathrm{L}$. Hyperbilirubinemia (total bilirubin, $1.9 \mathrm{mg} / \mathrm{dL}$ ) and an elevated inflammatory reaction (white blood cell count, 9,770/ $\mu \mathrm{L}$; C-reactive protein, 3.54 $\mathrm{mg} / \mathrm{dL}$ ) were also observed on laboratory examination (Table 1 ). Abdominal ultrasonography demonstrated a dilated common bile duct containing a stone of $30.2 \times 16 \times 12.9 \mathrm{~mm}$ having a linear hyperechoic internal area (Fig. 1a, b). Computed tomography (CT) scanning also revealed a common bile duct stone containing a characteristic bright dot in the transverse plane (Fig. 1c). A linear high-density area of a length of $20 \mathrm{~mm}$ was observed with partial maximum intensity projection (Fig. 1d), resulting in a diagnosis of acute cholangitis and obstructive jaundice due to a common bile duct stone containing a bone-like foreign body.

We administered antibiotics with fasting therapy for 8 days to treat the cholangitis. On day 9, we performed an endoscopic retrograde cholangiopancreatography (ERCP) using single balloon enteroscopy (Olympus Corporation; SIF-H290S; length, 1,520 mm; channel diameter, $3.2 \mathrm{~mm}$ ). This revealed a yellowish-brown, friable common bile duct stone cropping out of the choledochojejunostomy site (Fig. 2a). The cholangiogram showed an elongated filling defect in the bile duct (Fig. 3a). First, we dilated the choledochojejunostomy site using a 9-mm balloon catheter. After dilation, we inserted a stone basket catheter to diminish the size and extract the stone. After removing several friable stones, we noted a needleshaped substance trapped in the basket catheter (Fig. 2b). We carefully extracted the substance from the bile duct, collected it from the channel, and performed a subsequent balloon lithotomy. There was no evidence of residual stone on completion of the cholangiography. The foreign body was white, solid, needle shaped, and $20 \mathrm{~mm}$ in length (Fig. 3b). Fibrous connective tissue was revealed on histopathological imaging, and calcium phosphate was 


\section{Case Reports in Gastroenterology}

Case Rep Gastroenterol 2018;12:69-75

DOI: $10.1159 / 00048619$

(c) 2018 The Author(s). Published by S. Karger AG, Basel www.karger.com/crg

Sakakida et al.: A Bile Duct Stone Formation around a Fish Bone as a Nidus after Pancreatoduodenectomy

detected by component analysis. These results led us to determine that this foreign body was an ingested fish bone. The postoperative course was uneventful and the patient was discharged from our hospital on day 13.

\section{Discussion}

Foreign bodies in the common bile duct are rare, especially in patients with an altered gastrointestinal anatomy. They most commonly include residual objects from previous operations, such as a metal clip or suture material retained after laparoscopic cholecystectomy [1-3]. Internal stent tubes, which are occasionally placed at the site of anastomosis after choledochojejunostomy or pancreatojejunostomy to reduce bile duct pressure or prevent stenosis, are also reported [4]. Ingested food, as in our patient, may be another source of foreign bodies. However, previous reports have indicated that this occurs more often in patients without surgical histories [5-7]. Thus, iatrogenic factors are major contributors to bile duct foreign bodies. We were only able to find 5 reports of foreign bodies other than medical materials in patients with an altered gastrointestinal anatomy; 4 reports were of migrated fish or chicken bones acting as a nidus for stone formation [8-12], and 1 report was of a phytobezoar [13].

Following pancreatoduodenectomy, several steps are needed for an ingested fish bone to relocate to the bile duct. The bone must stray into the afferent loop and exhibit retrograde movement to the site of anastomosis and then remain in the bile duct. Ban et al. [14] reviewed the literature on bile duct foreign bodies and reported a $69.8 \%$ incidence of stone formation in patients with bile duct foreign bodies, and 100\% in patients with ingested food. We presume that fish bones can be easily caught in the duct because of their elongated shape and that anastomotic stenosis also influences retention, causing the bone to become a nidus for stone formation. However, most underlying mechanisms are still obscure.

Although visibility varies depending on the fish species, location, and orientation, ingested fish bones are difficult to identify by plain radiography. Ultrasonography and CT are useful for the diagnosis of fish bone impaction, as with our patient [15]. Ultrasonography reveals a dot or linear hyperechoic area, and a unique bright dot or bone density line can be seen on CT. Magnetic resonance imaging is inadequate because of its poor depiction of calcification. Therefore, it can be concluded that when CT or ultrasonography shows an unusual elongated stone containing a bright dot or bone density line, the possibility of stone formation around a fish bone should be considered. Pretreatment diagnosis of a fish bone in the bile duct is especially important for treatment selection. It is also important before endoscopic therapy, as fish bones should be safely removed from the bile duct and collected to avoid intestinal damage or perforation.

Conventional ERCP is challenging in patients with an altered gastrointestinal anatomy, leading to referral for percutaneous interventions or surgery. Single- and double-balloon enteroscopes have enabled us to perform diagnostic and therapeutic ERCP in more cases. In past reports, treatment for an ingested bone in the bile duct in patients with an altered gastrointestinal anatomy mostly involved surgery, and endoscopic therapy was performed in only one case [11]. Some of the past reports reveal the safety of removing needle-shaped objects by endoscopic treatment in patients without histories of surgery [6, 7]. They remark 
that the procedure's safety depends on whether the object can be removed parallel to the bile duct axis. In our case, this condition was fulfilled. Besides, it is difficult to remove needleshaped objects through a percutaneous pathway. Consequently, endoscopic therapy might be safer and more effective in this situation. In our patient, endoscopic therapy using a balloon enteroscope was useful for extracting the common bile duct stone and fish bone. We also succeeded in safely collecting the bone through the channel, thereby avoiding intestinal damage or perforation.

In conclusion, an unusual elongated bile duct stone, which contains a bright dot or bone density line on CT, should be considered as a common bile duct stone, potentially containing a fish bone nidus. In such a case, endoscopic therapy can be useful for safely treating the obstruction.

\section{Disclosure Statement}

The authors declare no conflicts of interest associated with this case report.

\section{References}

1 Okuyama K, Takahashi T, Nagata M, et al: A study of choledochal concrements formed around silk suture after cholecystectomy (in Japanese). Tan to Sui 1981;2:569-575.

2 Otani J, Kawai H, Uemura T, et al: A case of intrahepatic stone formed around a surgical suture needle (in Japanese). Nihon Rinsho Geka Gakkai Zasshi 1998;59:3080-3085.

-3 Fujita N, Noda Y, Kobayashi G, et al: Foreign bodies in the bile duct after laparoscopic cholecystectomy. Dig Endosc 1994;6:287-290.

4 Rezvani M, O'Moore PV, Pezzi CM: Late pancreaticojejunostomy stent migration and hepatic abscess after Whipple procedure. J Surg Educ 2007;64:220-223.

5 Kim YH, Kim YJ, Park WK, et al: Fish bone as nidus for stone formation the common bile duct: report of two cases. Korean J Radiol 2004;5:210-213.

6 Yoshida A, Fujii T, Shibata N, et al: A case of a fish bone in the common bile duct. Gastroenterol Endosc 2005;47:2191-2196.

7 Yoshida A, Ohba K, Morisaki T, et al: A case of a common bile duct stone caused by an ingested fish bone. Gastroenterol Endosc 2010;52:265-271.

8 Kakiuchi M, Iwai A, Akamine T, et al: A case of common bile duct stone caused by a fish bone. Nihon Rinsho Geka Gakkai Zasshi 1989;44:1955-1957.

-9 Zonnebelt S, Wolberg W: Ascending cholangitis secondary to a chicken bone lodged at the ampulla of Vater. Am J Surg 1981;141:610-611.

10 Kuga T, Oka K, Iguchi T, et al: A case report of the patient with foreign body (fish bone) in the intrahepatic bile duct after pylorus preserved pancreatoduodenectomy. Geka 2016;78:1123-1127.

11 Bamba H, Nakata T, Sato Y, et al: A case report of a bile duct stone whose formation was induced by a fish bone after pancreatoduodenectomy. Gastroenterol Endosc 2017;59:62-67.

12 Hori N, Matsuda T, Katsube R, et al: A case of a fish bone detected in the upper bile duct after gastrectomy and choledochoduodenostomy (in Japanese). Nihon Rinsho Geka Gakkai Zasshi 2016;77:2033-2038.

13 Garlipp B, Schulz HU, Böttcher S, et al: Phytobezoar in the common hepatic duct - rare cause of obstructive jaundice following pancreatoduodenectomy: case report and review of the literature (in German). Z Gastroenterol 2012;50:1166-1170.

14 Ban JL, Hirose FM, Benfield JR: Foreign bodies of the biliary tract: report of two patients and a review of the literature. Ann Surg 1972;176:102-107.

15 Lue AJ, Fang WD, Manolidis S: Use of plain radiography and computed tomography to identified fish bone foreign bodies. Otolaryngol Head Neck Surg 2000;123:435-438. 


\section{Case Reports in Gastroenterology}
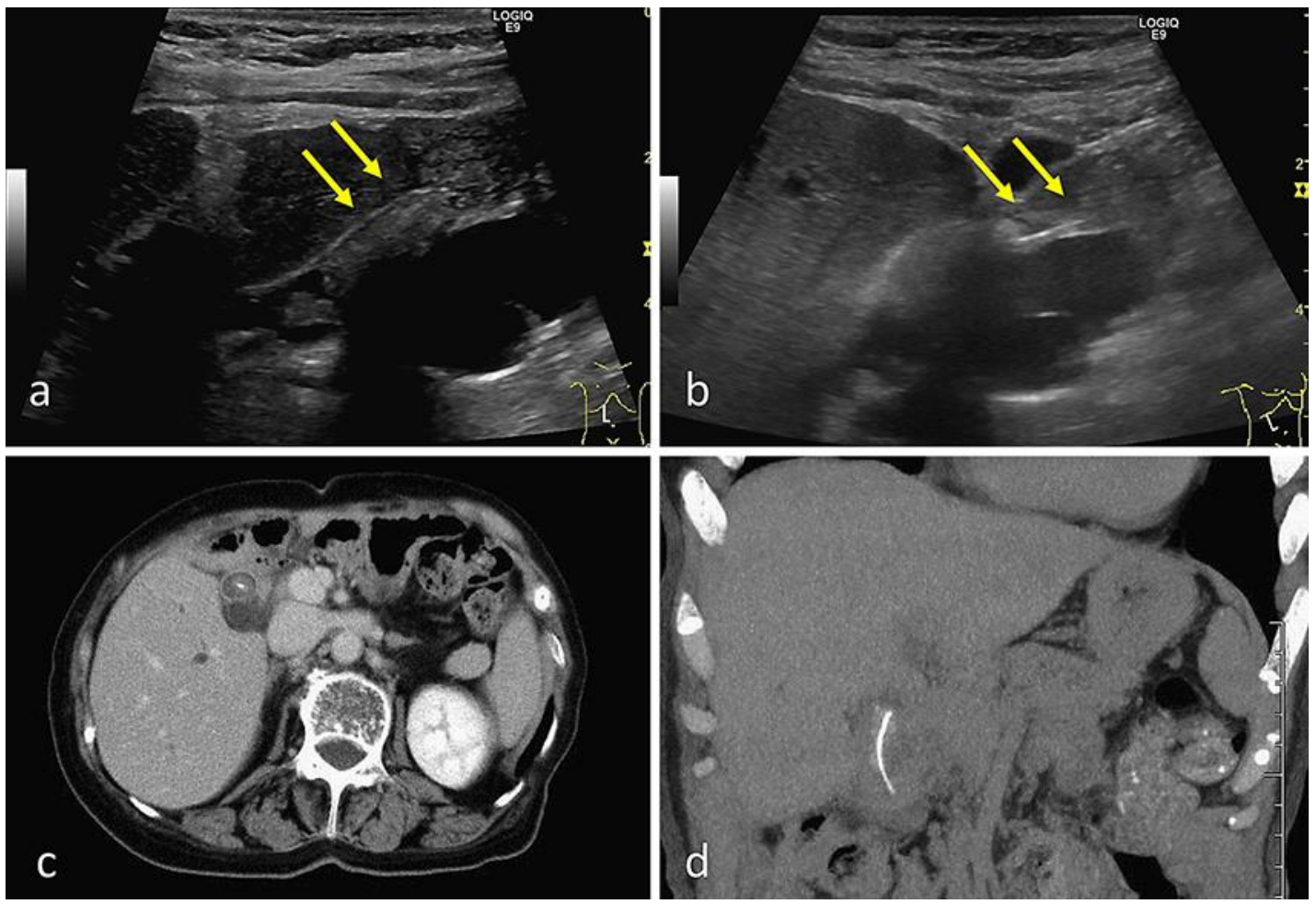

Fig. 1. a Ultrasonography revealed an elongated bile duct stone (yellow arrows). b A bright hyperechoic line is evident inside the stone (yellow arrows). c Computed tomography scan showing a bile duct stone, containing a characteristic bright dot. d In partial maximum intensity projection, a 20-mm, linear, highdensity area is shown. 


\section{Case Reports in Gastroenterology}

Case Rep Gastroenterol 2018;12:69-75

(C) 2018 The Author(s). Published by S. Karger AG, Basel www.karger.com/crg

Sakakida et al.: A Bile Duct Stone Formation around a Fish Bone as a Nidus after Pancreatoduodenectomy
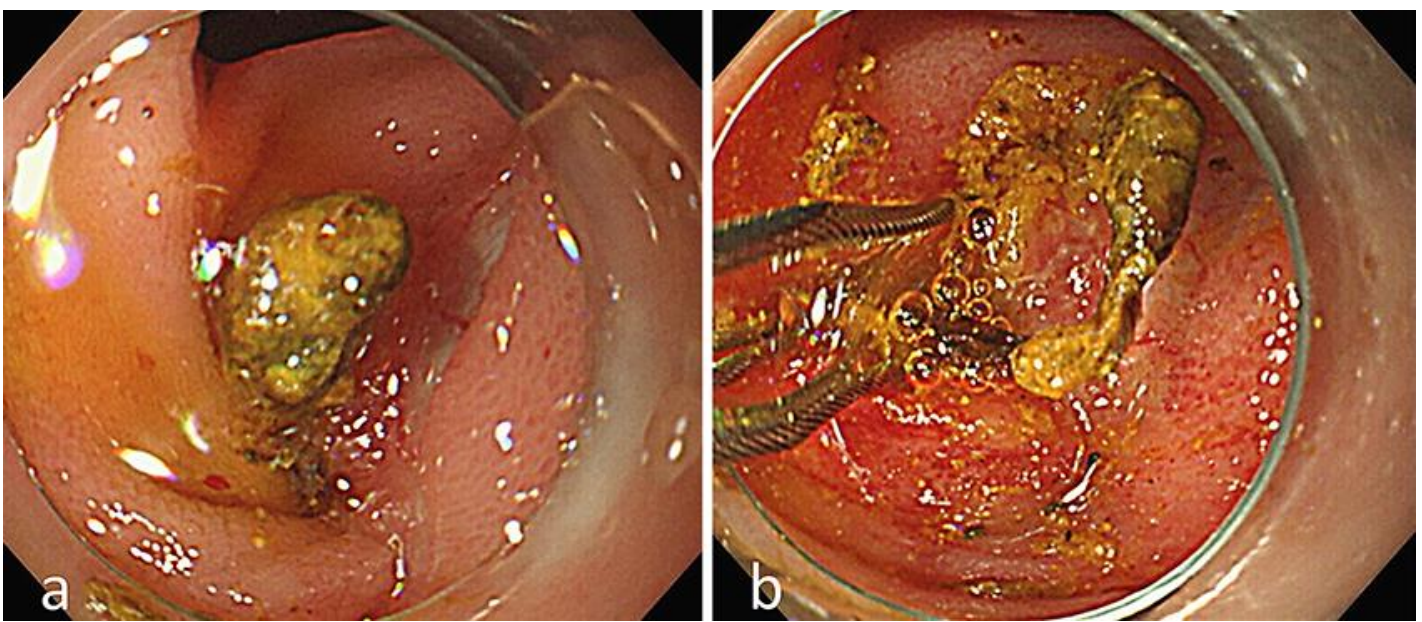

Fig. 2. a A yellowish-brown, friable stone is cropping out of the choledochojejunostomy site. b A needleshaped substance trapped in the basket catheter is visible.
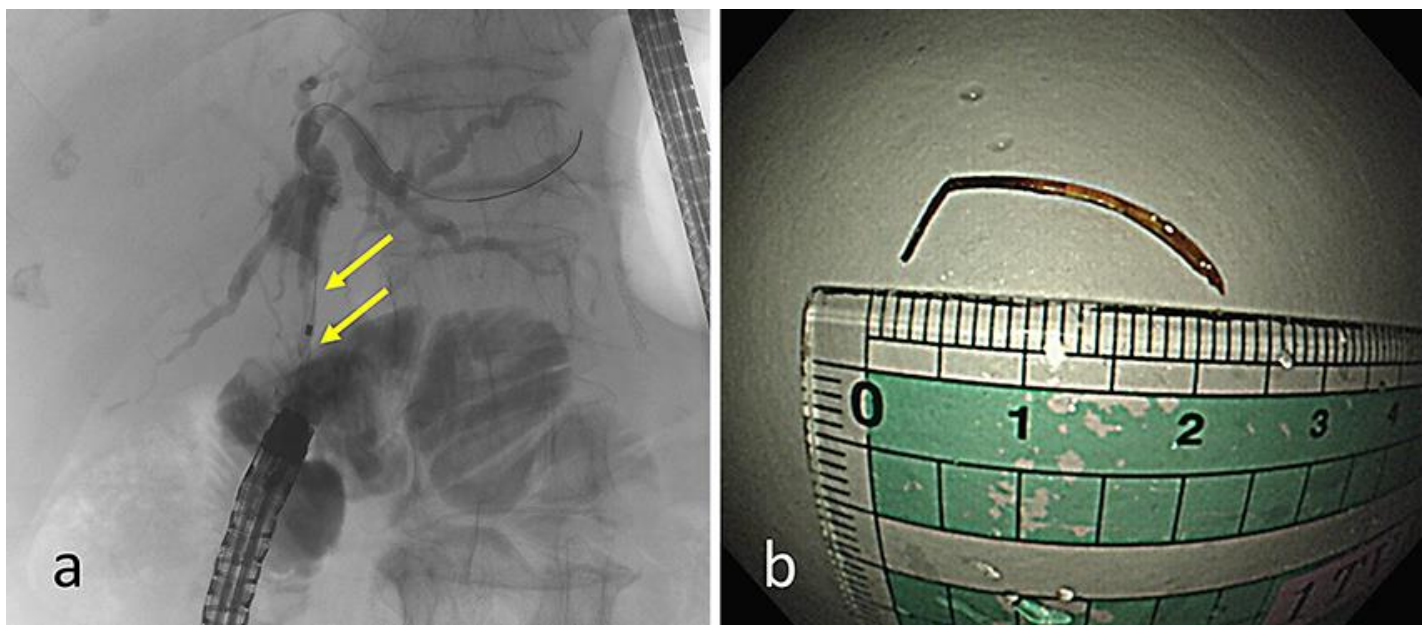

Fig. 3. a Cholangiogram showing an elongated filling defect in the bile duct (yellow arrows). $\mathbf{b}$ The needleshaped substance was white, solid, and $20 \mathrm{~mm}$ in length, suggestive of a fish bone. 
Sakakida et al.: A Bile Duct Stone Formation around a Fish Bone as a Nidus after

Pancreatoduodenectomy

Table 1. Laboratory findings on admission

\begin{tabular}{llllll}
\hline RBC & $373 / \mu \mathrm{L}$ & $\mathrm{TP}$ & $6.4 \mathrm{~g} / \mathrm{dL}$ & $\mathrm{Na}$ & $135 \mathrm{mEq} / \mathrm{L}$ \\
$\mathrm{Hb}$ & $10.4 \mathrm{ng} / \mathrm{mL}$ & $\mathrm{Alb}$ & $3.2 \mathrm{~g} / \mathrm{dL}$ & $\mathrm{K}$ & $3.9 \mathrm{mEq} / \mathrm{L}$ \\
$\mathrm{Hct}$ & $31.6 \%$ & $\mathrm{AST}$ & $85 \mathrm{IU} / \mathrm{L}$ & $\mathrm{Cl}$ & $103 \mathrm{mEq} / \mathrm{L}$ \\
$\mathrm{MCV}$ & $84.7 \mathrm{fL}$ & $\mathrm{ALT}$ & $77 \mathrm{IU} / \mathrm{L}$ & $\mathrm{CRP}$ & $3.51 \mathrm{mg} / \mathrm{dL}$ \\
$\mathrm{MCH}$ & $27.9 \mathrm{pg}$ & $\mathrm{LDH}$ & $209 \mathrm{IU} / \mathrm{L}$ & $\mathrm{INR}$ & 1.0 \\
$\mathrm{MCHC}$ & $32.9 \%$ & $\mathrm{ALP}$ & $2,478 \mathrm{IU} / \mathrm{L}$ & $\mathrm{PT}$ & $92 \%$ \\
WBC & $9,770 / \mu \mathrm{L}$ & $\gamma-\mathrm{GTP}$ & $627 \mathrm{IU} / \mathrm{L}$ & $\mathrm{Fib}$ & $431 \mathrm{mg} / \mathrm{dL}$ \\
Neut & $75.6 \%$ & $\mathrm{~T}-\mathrm{Bil}$ & $1.9 \mathrm{mg} / \mathrm{dL}$ & $\mathrm{HBs}-\mathrm{Ag}$ & negative \\
Ly & $13.8 \%$ & D-Bil & $1.1 \mathrm{mg} / \mathrm{dL}$ & $\mathrm{HCV}-\mathrm{Ab}$ & negative \\
Mono & $7.4 \%$ & Amy & $58 \mathrm{IU} / \mathrm{L}$ & & \\
Eo & $3.0 \%$ & BUN & $6 \mathrm{mg} / \mathrm{dL}$ & & \\
Plt & $32.6 / \mu \mathrm{L}$ & Cre & $0.52 \mathrm{mg} / \mathrm{dL}$ & & \\
\hline
\end{tabular}

